\title{
Using the MAP-IT Framework for Implementing a Homeschool Physical Education Program at a University Campus
}

\author{
${ }^{1}$ Matthew T. Buns, ${ }^{2}$ Cherie Pettitt, and ${ }^{3}$ Jedediah Blanton \\ ${ }^{1}$ Matthew T. Buns is an Assistant Professor of Kinesiology and Health Science at Concordia \\ University, St. Paul. \\ ${ }^{2}$ Cherie Pettitt is an Assistant Professor of Human Performance at Minnesota State University, \\ Mankato. \\ ${ }^{3}$ Jedediah Blanton is an Assistant Professor of Exercise Psychology at University of Tennessee- \\ Knoxville.
}

\begin{abstract}
Universities are actively seeking new ways to provide meaningful field experience opportunities. According to the National Home Education Research Institute (2010), homeschooling has grown from nearly extinct in the United States in the 1970's to now over 2 million school-aged students. Thus, on-campus homeschool physical education programs serve as a viable mechanism for supplementing physical education teacher education (PETE) program requirements while providing valuable physical education opportunities to homeschooled students. The purpose of this article is to describe the MAP-IT Framework (American College Health Association, 2012) for the design and implementation of a contemporary on-campus homeschool physical education program. This guide is intended for PETE instructors who are considering initiating an oncampus homeschool physical education program. The MAP-IT framework has been used to plan and evaluate public health interventions to achieve community health objectives and offers a strong outline for PETE instructors to create an effective and sustainable on-campus homeschool physical education program.
\end{abstract}

Keywords: Homeschool Physical Education, MAP-IT, Teacher Education, Field Experience

Teacher education programs in all disciplines collaborate with a network of partner K-12 schools where pre-service teachers complete field experiences. These field experiences allow future teachers to apply best practices and demonstrate learned skills and instructional methods in real-world settings. As a result, many schools in proximity to university teacher education programs are often inundated with undergraduate observers and student-teachers. Many cooperating teachers are overwhelmed with the number of pre-service teachers they are asked to mentor. Thus, universities are actively seeking new ways to provide meaningful field experience opportunities. One such opportunity may include a partnership with community homeschooling parents and children.

Homeschooling has been described as both the "oldest" and "newest" form of education (Angelis, 2008). According to the National Home Education Research Institute (2010), homeschooling has grown from nearly extinct in the United States in the 1970's to now over 2 million school-aged students. The report states:

- Approximately 3.8 percent of U.S. K-12 students were homeschooled in spring of 2010.

- Nearly 2 million K-12 students were homeschooled in spring of 2010.

- The 7 percent growth rate for homeschool education far exceeds the 0.59 percent growth rate of traditional school enrollment (from 2007-2010).

As a result, homeschool partnerships are beginning to form with local school districts and universities. States are willing to offer extracurricular activities and classroom instruction to homeschool students. University campus homeschool physical education programs serve as a viable mechanism for supplementing physical education teacher education (PETE) program requirements while providing valuable physical education opportunities to homeschooled students.

The purpose of this article is to describe the MAP-IT Framework (American College Health Association, 2012) for the design and implementation of a contemporary on-campus homeschool physical education program. This guide is intended for PETE instructors who are considering 
initiating an on-campus homeschool physical education program. Specific implementation strategies and ancillaries are provided.

\section{MAP-IT FRAMEWORK}

In 2000, McKethan, Everhart, and Herman outlined on-campus home school physical education guidelines in their article, "Starting a Home-School Physical Education Clinical Program on Your Campus. 'Fifteen years have since passed, and the need to revisit this topic is warranted. This article expands on McKethan, Everhart, and Herman's (2000) work by providing a more structured framework. Adapted from Healthy People 2020(USHDDS, n.d.), the MAP-IT framework has been used to plan and evaluate public health interventions to achieve community health objectives. According to the American College Health Association (2012), although "no two campus initiatives are exactly alike", many share a similar path to success: Mobilize, Assess, Plan, Implement, and Track. The MAP-IT Framework offers a strong outline for PETE instructors to create an effective and sustainable on-campus homeschool physical education program. Facilitators may wish to consider the four key elements in orchestrating a successful capacity building initiative as suggested by the Foundation Center: a) the desired outcome or defining goal; b) the change strategy; c) the internal and external champions guiding the efforts; and d) the resources necessary to achieve the desired outcome (Light and Hubbard, 2004). Below, each concept of the MAP-IT Framework is explained and examples are provided on how to apply the framework as a guide for developing an on-campus homeschool physical education program.

\section{MOBILIZE (STEP 1)}

Begin by Mobilizing Key Individuals and Organizations into a Coalition: Create a list of potential campus, community, and homeschool partners to join the program. In most instances, a simple Web search will allow you to find a local homeschool association in almost any community. These associations exist to provide support for teaching ideas and educational resources among parents. Parents are usually not prepared to provide high-quality physical education experiences for their children at home. Gregory (2005) revealed a need for better physical education instruction in the homeschool setting and recommended more and better interaction between homeschoolers and physical education professionals.

A quality homeschool physical education program requires an initial face-to-face or virtual meeting to ensure that goals and procedures are determined, communicated, and applied. Students and parents often have misconceptions about the nature of physical education (Darst, Pangrazi, Brusseau, and Erwin, 2012), so clarifying all aspects of the homeschool program is helpful. An important consideration in selecting a common vision for the program is to examine the desires, characteristics, and interests of the parents and students participating in the program. Previously, communities came together and set aside land and built schools because they wanted their children to acquire certain knowledge, attitudes, and skills. The role of the physical education instructor is to meet the mission of the school while helping students achieve the national content standards for physical education (AAHPERD, 2014).

Next, Identify Roles for Parents, Students, and Assign Responsibilities: The lead PETE instructor in this initiative would be an internal champion, and may wish to recruit other faculty or students to help organize the programming. Another crucial element toward the success of this programming are the external "champions" (Light and Hubbard, 2004). Connecting with an area homeschool association and identifying one or more "parental champions" to help market your program, utilize their established communication tools (email lists, websites, etc.), and even seek help in arranging carpools to campus can prove to be key in bringing this community to the university.

One of the major responsibilities for pre-service teachers is a willingness to collaborate. Collaboration among program instructors is vital to the creation of a well-aligned and effective program that is enjoyed by students and parents. Clear organization and strong instruction are needed in the program to maintain high enrollment and engagement. If there are timeline issues that make face-to-face collaboration among instructors difficult, there are a number of useful sources available in virtual space that allow teachers to work together asynchronously (e.g., Blackboard discussion posts) or syncrhounsly (e.g., WebEx). Depending on student enrollment and the number of physical education majors available to teach in the program, it is recommended that instructors are assigned to one of at least four cohort teaching groups that will share equal time teaching and observing each grade level. Following a collaborative, student-centered model, pre-service teacher responsibilities can be self- 
selected within each teaching group during regular course meetings. Figure 1provides a sample assignment instructions for students required to teach in the homeschool program as part of class.

Figure 1. Sample Pre-service Teacher Assignment Instructions

Your Task: You will teach as part of a K-12 Home School Physical Education Program. This will require you to develop a lesson plan for each lesson you lead. You will be evaluated on both your instruction and your ability to develop an effective and developmentally appropriate lesson plan.

Instruction. In small groups, you will be formally evaluated while teaching several physical education lessons. Each lesson should last approximately 60 minutes. Absence on the day one is scheduled to teach, non-participation in the lesson or subsequent discussion, or failure to submit a written lesson plan will result in the loss of points in this area. Within your group, you will work to designate a "lead" teacher for each week to share the responsibility of lesson planning and teaching throughout the semester. It is the "lead" teacher's responsibility to develop and submit lesson plans but keep in mind that each lesson is a shared responsibility among group members. You are responsible for acquiring all necessary materials in advance-contact the equipment manager to ensure facility and equipment availability.

Lesson Plan. Develop one lesson plan each week. This lesson plan should include National Content Standards (at least 2 standards) and align with the specific lesson topic (e.g., hockey) and curricular model (e.g., tactical games approach) assigned to you. Each lesson plan must be typed and submitted as a hard copy to the instructor on the day you teach.

Parental "buy-in" is a necessary step towards implementing a homeschool physical education program. See Figure 2 for a sample parent interest letter. The recruitment of instructors may occur organically when the program is scheduled congruently with a physical education methods course each semester (fall and spring). There may be other constituents not enrolled in the methods course (e.g., graduate students) that would benefit from the experience and contribute in meaningful ways to the organization and management of the program.

Figure 2. Sample Letter to Parents

\section{Dear Parent,}

Warm wishes from the [insert department] at [insert university]. As you plan for the upcoming year, I want to let you know about our Homeschool Physical Education Program. Physical education is an integral part of the total educational program that contributes, primarily through physical activity experiences, to the total growth and development of all students.

Our Homeschool Physical Education Program makes four unique contributions to the lives of students:

* Knowledge for living an active and healthy lifestyle

* Competency and confidence in a variety of skills that can be used for physical activity the rest of their lives

* Achievement and enjoyment of daily physical activity

* Development and reinforcement of pro-social behaviors

If these contributions are not accomplished in physical education, they may not be realized elsewhere in the curriculum. Our instructors (physical education majors) have a commitment to develop and teach a systematically organized curriculum for kindergarten through grade twelve that favorably influences all students and enhances their physical activity habits. Please feel free to visit our web site at [insert web address] to learn more about our university and the homeschool physical education program.

I hope to hear from you soon!

Your Name | Your Department

Your University/Contact Information

\section{ASSESS (STEP 2)}

Assess Both Needs and Resources in Your Campus Community: The University of Kansas "Work Group for Community Health and Development" (2014) provides guidance for developing a plan for assessing local needs and resources. An assessment helps to uncover not only program needs and resources, but will also help you understand how to utilize resources that are already available to your program. Resources include anything that is used to improve the quality of the program. Here is a list of potential questions to ask to determine resources (Figure 3): 
Figure 3. Potential Questions to Ask to Determine Resources

1. Who are the people we may need help from to be successful?

2. What are organizations in our community that have supporting or aligned interests?

3. What are the skills or strengths of our group?

4. What physical resources do we have available to us?

Each campus has its own needs and resources - a unique blend of equipment, buildings, fields, and individuals that define it. Work with fellow faculty and staff members, local homeschool associations, pre-service teachers, and parents to create a list of potential assets in your campus community that benefit the program. These working partners include:

1. Kinesiology and Education Departments

2. Health and Physical Education Students

3. Area Homeschool Families

4. Facility Services (parking permits) and Printing Services (campus maps)

5. Recognition from several local media outlets to bolster enrollment

You might discover that your campus has much more interest in the homeschool physical education program than you first perceived - and many university constituents are eager to help. Parents tend to feel good about helping to provide real-world experience for teacher candidates, especially those who might go on to teach in non-traditional settings.

Lastly, having a thorough review of available and needed resources is recommended. Instructors should have access to enough equipment to fully satisfy a "normal" physical education class on campus. Also, be sure you can have enough students available at the same time to administer the program; consider aligning this experience with a required course. Additionally, take time to survey your campus environment to gather parking information for parents, and other resources that parents can utilize during program meetings. By offering a free program and parking accommodations, constituents are reassured of the program's commitment to service and not financial gain. Although the program is geared towards the teaching and learning process for university students, parents may simultaneously benefit from a physical activity "program" of their own if granted access to campus facilities (jogging track, weight room, etc.). Parents can form physical activity groups of their own and utilize campus facilities during the physical education instruction time.

\section{Plan (STEP 3)}

Determine the Vision and Goals of the Program: A goal is defined as something toward which you direct your efforts in order to achieve a desired outcome (Webster's Dictionary,1993). Most experts would agree that goal setting is a crucial part of success in education and performance. "Aim at nothing and you'll probably hit it," someone said referring to the importance of goals. Another quotation often mentioned is, "If you don't know where you're going, you'll probably end up somewhere else." And finally, "If you fail to plan, you plan to fail."

The objective of the university campus homeschool physical education program is twofold:

1. To prepare physical education majors to develop the skills necessary to teach and continue improving as a teacher.

2. To support quality physical education programs for homeschool children to promote their health and well-being

Established goals will help keep the group on task and be successful. Where you are aiming will often help determine what your physical education program becomes.

For the programming described here, we suggest having two guiding goals: (1) increase opportunities for pre-service teachers to facilitate classroom experiences, and (2) increase structured physical activity opportunities for area homeschool children. The "change strategy" would be to bring these pre-service teachers and homeschool children together on university campuses during PETE course meetings, rather than sending pre-service teachers out into the area schools.

Homeschoolers spend little time in physical education instruction and pre-service teachers need to be prepared to navigate the content and pedagogy that are an integral part of PETE programming. Thus, this programming plan provides intentional and mutually beneficial experiences for homeschoolers and pre-service teachers. 


\section{IMPLEMENT (STEP 4)}

First, Create a Detailed Work Plan that Lays Out Concrete Action Steps, Identifies Who is Responsible for Completing them, and Sets a Timeline and/or Deadlines: Although many program instructors (pre-service teachers) will come and go each semester, the university PETE instructor remains the same and provides solidarity. Thus, the PETE instructor is more equipped than the pre-service teachers to take a leading role on curriculum development (although student input is critical). In small groups, pre-service teachers develop a complete lesson plan for each weekly lesson and are evaluated on both his or her teaching and ability to develop an effective and developmentally appropriate lesson plan. Each teaching group focuses on developmentally appropriate learning objectives that guide instruction, and all lessons should be aligned with the national content standards for physical education. Figure 4 provides a sample semester teaching schedule for the homeschool physical education program. Homeschool students can be grouped and taught in specific age and maturational ranges in a variety of settings for 8-10 weeks each semester; they benefit from a developmentally appropriate curriculum that is aligned both vertically and horizontally (this is a shared responsibility).

\begin{tabular}{|c|c|c|c|}
\hline Date & & Lesson Focus & Group \\
\hline \multirow[t]{4}{*}{1} & K-1 & Manipulative Skills Using Hoops & 1 \\
\hline & $2-3$ & Throwing Skills/Games & 2 \\
\hline & 4-6 & Football Skills and Lead-up Activities & 3 \\
\hline & $7-12$ & Soccer or Flag Football Skills and Lead-up Activities & 4 \\
\hline \multirow[t]{4}{*}{2} & $\mathrm{~K}-1$ & Throwing Skills/Games & 1 \\
\hline & $2-3$ & Manipulative Skills Using Wands and Hoops & 2 \\
\hline & $4-6$ & Long-Rope Jumping Skills/Games & 3 \\
\hline & $7-12$ & Soccer or Flag Football Game Play & 4 \\
\hline \multirow[t]{4}{*}{3} & $\mathrm{~K}-1$ & Manipulative Skills Using Beanbags & 2 \\
\hline & $2-3$ & Football Skills and Lead-up Activities & 3 \\
\hline & $4-6$ & Soccer Skills and Lead-up Activities & 4 \\
\hline & $7-12$ & Volleyball Skills and Lead-up Activities & 1 \\
\hline \multirow[t]{4}{*}{4} & $\mathrm{~K}-1$ & Manipulative Skills Using Playground Balls & 2 \\
\hline & $2-3$ & Soccer Skills and Lead-up Activities & 3 \\
\hline & $4-6$ & Gymnastics skills & 4 \\
\hline & $7-12$ & Volleyball Game Play & 1 \\
\hline \multirow[t]{4}{*}{5} & $\mathrm{~K}-1$ & Movements Skills/Games & 3 \\
\hline & $2-3$ & Fundamental Skills Using a Parachute & 4 \\
\hline & $4-6$ & Basketball Skills and Lead-up Activities & 1 \\
\hline & $7-12$ & Badminton Skills and Lead-up Activities & 2 \\
\hline \multirow[t]{4}{*}{6} & $\mathrm{~K}-1$ & Gymnastics Skills & 3 \\
\hline & $2-3$ & Rhythmic Movement Skills & 4 \\
\hline & $4-6$ & Rhythmic Movement Skills & 1 \\
\hline & $7-12$ & Badminton Game Play & 2 \\
\hline \multirow[t]{4}{*}{7} & $\mathrm{~K}-1$ & Kicking, Trapping, Bowling, and Rolling & 4 \\
\hline & $2-3$ & Gymnastics Skills & 1 \\
\hline & $4-6$ & Throwing Skills/Games & 2 \\
\hline & $7-12$ & Speed-Away & 3 \\
\hline \multirow[t]{4}{*}{8} & $\mathrm{~K}-1$ & Fundamental Skills Using Parachute Activities & 4 \\
\hline & $2-3$ & Hockey Skills and Lead-up Activities & 1 \\
\hline & $4-6$ & Cooperative Game Skills & 2 \\
\hline & $7-12$ & Team Handball Skills and Game Play & 3 \\
\hline
\end{tabular}

Note: Lesson Focus adapted from Pangrazi, R., \& Beighle, A. (2013).Dynamic physical education for elementary school children. San Francisco, CA: Benjamin Cummings. 


\section{TRACK (STEP 5)}

Plan Two Types of Evaluations to Measure Aand Track Your Progress Over Time: 1) Teaching Evaluation and 2) Program Evaluation: Teaching evaluations can help the instructor determine if pre-service teachers are able to apply what has been learned in the classroom about expert teacherspositioning, scanning, observing, integrating, cueing, demonstrating, reinforcing and giving feedback. Program evaluations are also necessary to help determine if the program has been effective in achieving the aforementioned goals. Dzewaltowski and Rosenkranz (2014) describe a framework for monitoring programming designed to enhance youth development through physical activity, with an emphasis on the youth-environment interaction and advising more rigorous methods to describe program effectiveness. PETE instructors could collaborate with researchers to more systematically monitor their program and make necessary changes to best enhance the youth experience. Pangrazi and Beighle (2013) offer a sample physical education program evaluation that can be administered to parents to identify programs strengths and weaknesses. In addition to traditional instruction and lesson planning evaluations, self- or peer-evaluations (Figure 5) afford additional opportunities for preservice teachers to reflect on their own teaching and evaluate themselves and others

Pre-service teachers may be required to develop and use assessments for each lesson they teach by applying best practices for validity, reliability, and objectivity. Furthermore, this provides practice opportunities for pre-service teachers to determine how information gathered from psychomotor, cognitive, and affective domains will be used. Evaluation and assessment are conducted for many reasons in addition to measuring progress toward standards, benchmarks and student learning.

\section{Figure 5. Peer-Evaluation}

1. What were the lesson objectives (in other words, what should the students be able to do at the conclusion of this lesson)?

2. Were these objectives accomplished? Could most of the students successfully complete the task most of the time? Did the teachers communicate the objectives to the students, both at the beginning and end of the lesson? (Briefly explain your response)

3. What cues were used to get the student's attention? List at least one management cue, and several instructional cues. Were they effective? Be specific!

4. Did the students successfully practice the skills presented? What correction was offered to those who were either not correctly demonstrating the skill (not able to) or those who were simply off task?

5. What types of reinforcement did the teachers use? What feedback did the teachers offer? Was it constructive/ consistent throughout the lesson?

6. Out of the total lesson time, how long were the children actually engaged in physical activity? Was this acceptable? Give an example(s) of when considerable time was lost (listening to directions, water breaks, equipment distribution, transitions, standing in line, etc.) and a suggestion for how to increase activity during that time.

7. Were the teachers enthusiastic? Were they smiling at the students, interacting with the students, etc.?

8. What areas of the lesson could use improvement (group preparedness, transitions, organization, voice quality, lesson pacing, feedback, etc.)? Explain.

9. What aspects of the lesson were particularly impressive (group preparedness, transitions, organization, voice qualify, lesson pacing, feedback, etc.)?

Tracking helps to provide assurances that the program goals are met, both for children and instructors. Without tracking, it is impossible to determine parental satisfaction with the program and whether or not program instructors can apply knowledge about how children grow, move, and learn. Finally, program leaders should share progress with all pre-service teachers and parents by issuing a press release or announcement. Celebrate your successes! Set a goal for program enrollment to grow each semester and utilize local media outlets (newspaper, radio, and television) and administrator support for recognition.

\section{SUMMARY}

On-campus homeschool programs can help pre-service teachers gain valuable real-world experience in areas such as curriculum development and lesson planning, evaluation, and communicating with parents. The MAP-IT Framework provides direction for implementing a homeschool physical education programas part of or in addition to any elementary or secondary physical education methods course. For many homeschoolers, this may be the only physical education they receive. The value homeschool parents and associations place on education can in turn help PETE programs improve the quality of teachers they produce. 


\section{REFERENCES}

American Alliance of Health, Physical Education, Recreation, and Dance. (2014). National standards \& grade-level outcomes for K-12 physical education. Champaign, IL: Human Kinetics.

American College Health Association. (2012). Healthy Campus 2020. Retrieve July 1, 2014, from http://healthypeople.gov/2020/implementing/default.aspx.

Angelis, K. L. (2008). Home schooling: Are partnerships possible? Unpublished doctoral dissertation, University of Maryland, College Park, MD.

Darst, P.W. \& Pangrazi,R.P., Brusseau, T., and Erwin, H. (2014). Dynamic physical education for secondary school students (8th Ed.). Benjamin Cummings: Pearson.

Dzewaltowski, D., \& Rosenkranz, R. (2014). Youth development: An approach for physical activity behavioral science. Kinesiology Review, 3, 1, 92-100. doi: 10.1123/kr.2014-0042

Goal. (1993). Webster's Dictionary (p. 76, $1^{\text {st }}$ ed.). Ashland, OH: Landoll Publishing

Gregory, E.R. (2005). Curriculum and the status of physical education in homeschooling. Teaching and Leadership - Dissertations. Paper 36. Retrieved December 15, 2014 from http:// surface.syr .edu/tl_etd/36

KU Work Group for Community Health and Development. (2014). Chapter 3, Section 10: Conducting Concerns Surveys. Lawrence, KS: University of Kansas. Retrieved January 2, 2014, from the Community Tool Box: http://ctb.ku.edu/en/table-of-contents/assessment/assessing-communityne...

Light, P., \& Hubbard, E. (2004). The capacity building challenge: A research perspective. In P. Patrizi, K. Sherwood, \& A. Spector (Eds.) Practice Matter: The Improving Philanthropy Project (Report 7). Foundation Center. Retrieved from: http://foundationcenter.org/ gain knowledge/ practicematters/

Lyman, I. Home schooling back to the future? [Electronic version]. Cato Policy Analysis, No.294.

McKethan, R., Everhart, B., \& Herman, J. (2000). Starting a Home-School Physical Education Clinical Program on Your Campus. Journal of Physical Education, Recreation, and Dance, 71, $8,38-44$.

Pangrazi, R., \& Beighle, A. (2013). Dynamic physical education for elementary school children. San Francisco, CA: Benjamin Cummings.

U.S. Department of Health and Human Services, Office of Disease Prevention and Health Promotion. (n.d.). Healthy People 2020. Retrieved May 20, 2012 from http://www.healthypeople.gov 